\title{
Interannual sedimentary effluxes of alkalinity in the southern North Sea: model results compared with summer observations
}

\author{
Johannes Pätsch ${ }^{1}$, Wilfried Kühn ${ }^{1}$, and Katharina Dorothea Six ${ }^{2}$ \\ ${ }^{1}$ Theoretical Oceanography, Institute of Oceanography, University of Hamburg, Hamburg, Germany \\ ${ }^{2}$ The Ocean in the Earth System, Max Planck Institute for Meteorology, Hamburg, Germany \\ Correspondence: Johannes Pätsch (johannes.paetsch@uni-hamburg.de)
}

Received: 30 January 2018 - Discussion started: 5 February 2018

Revised: 20 April 2018 - Accepted: 15 May 2018 - Published: 4 June 2018

\begin{abstract}
For the sediments of the central and southern North Sea different sources of alkalinity generation are quantified by a regional modelling system for the period 20002014. For this purpose a formerly global ocean sediment model coupled with a pelagic ecosystem model is adapted to shelf sea dynamics, where much larger turnover rates than in the open and deep ocean occur. To track alkalinity changes due to different nitrogen-related processes, the open ocean sediment model was extended by the state variables particulate organic nitrogen (PON) and ammonium. Directly measured alkalinity fluxes and those derived from $\mathrm{Ra}$ isotope flux observation from the sediment into the pelagic are reproduced by the model system, but calcite building and calcite dissolution are underestimated. Both fluxes cancel out in terms of alkalinity generation and consumption. Other simulated processes altering alkalinity in the sediment, like net sulfate reduction, denitrification, nitrification, and aerobic degradation, are quantified and compare well with corresponding fluxes derived from observations. Most of these fluxes exhibit a strong positive gradient from the open North Sea to the coast, where large rivers drain nutrients and organic matter. Atmospheric nitrogen deposition also shows a positive gradient from the open sea towards land and supports alkalinity generation in the sediments. An additional source of spatial variability is introduced by the use of a 3-D heterogenous porosity field. Due to realistic porosity variations $(0.3-0.5)$ the alkalinity fluxes vary by about $4 \%$. The strongest impact on interannual variations of alkalinity fluxes is exhibited by the temporal varying nitrogen inputs from large rivers directly governing the nitrate concentrations in the coastal bottom water, thus providing nitrate necessary for benthic denitrification. Over the time investigated the alka-
\end{abstract}

linity effluxes decrease due to the decrease in the nitrogen supply by the rivers.

\section{Introduction}

Alkalinity generation from anaerobic degradation in coastal sediments favours the marine uptake capacity for atmospheric $\mathrm{CO}_{2}$. This is because these paths of organic matter degradation include irreversible processes like $\mathrm{N}_{2}$ production and loss of reduced sulfate products like pyrite and hydrogen sulfide.

In September 2011 and June 2012 (Brenner et al., 2016) measured alkalinity fluxes from the North Sea sediment using several sediment cores. For the southern North Sea they found a mean flux of $6.3 \mathrm{mmol} \mathrm{m}^{-2} \mathrm{~d}^{-1}$. Alkalinity effluxes into the pelagic system could partly determine the relatively high surface alkalinity concentrations (Fig. 1a) in the southern North Sea as observed by (Thomas et al., 2009) in September 2001. Together with observed concentrations of dissolved inorganic carbon (DIC) (Bozec et al., 2006) these surface alkalinity concentrations can be translated into $\Delta p \mathrm{CO}_{2}$ values $\left(p \mathrm{CO}_{2}{ }^{\text {ocean }}-p \mathrm{CO}_{2}{ }^{\text {atmosphere }}\right)$ which are mainly responsible for the air-sea exchange of $\mathrm{CO}_{2}$ between ocean and atmosphere (Fig. 1b). In the southern North Sea positive values indicate oversaturation and thus outgassing, whereas in the northern parts negative values result in an uptake of atmospheric $\mathrm{CO}_{2}$. When in a simple thought experiment the observed alkalinity fluxes by (Brenner et al., 2016) would be reduced by $50 \%$ from the beginning of the year, the alkalinity concentrations, especially in the shallow southern North Sea, would be reduced (Fig. 1c) 

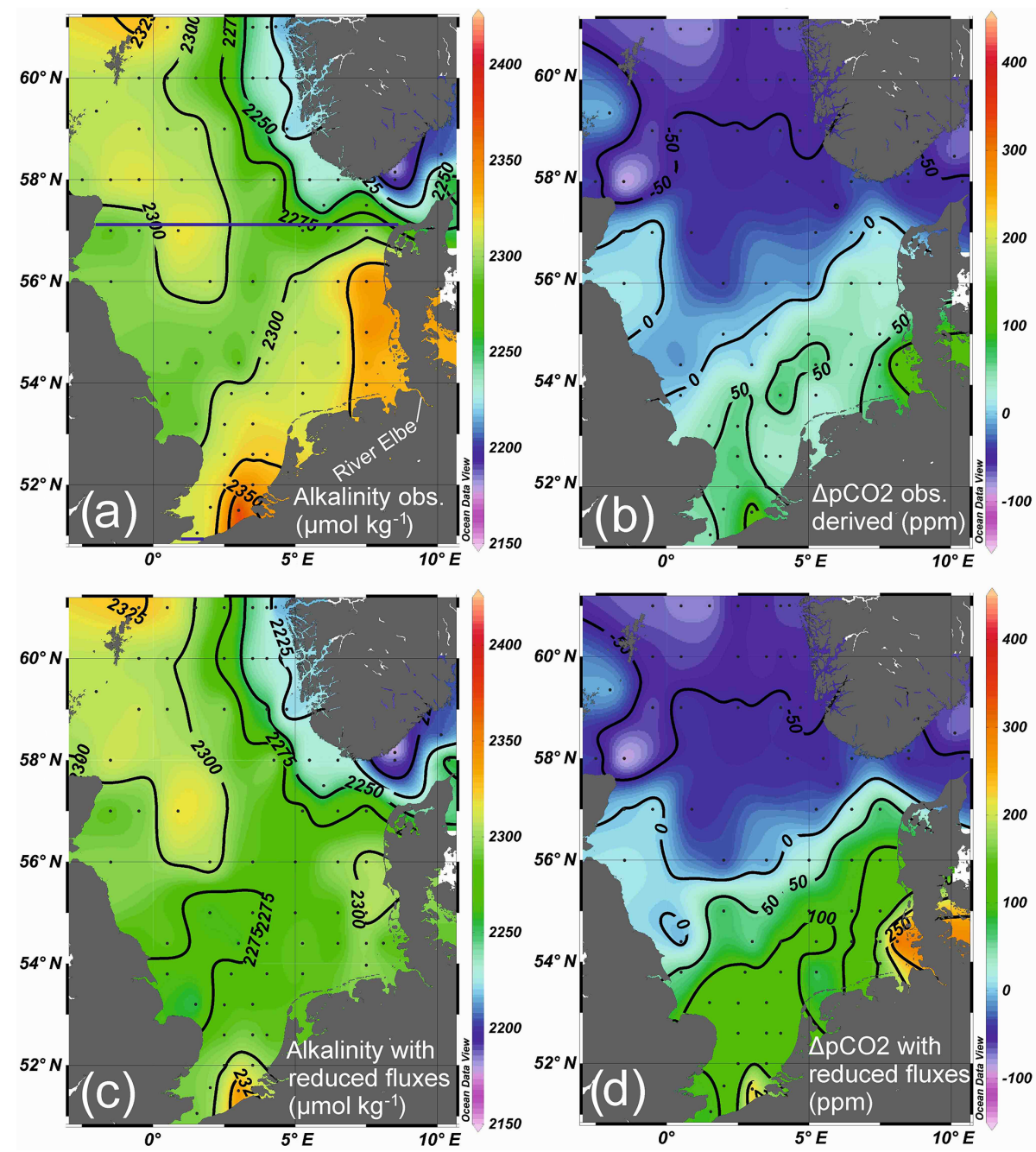

Figure 1. (a) Surface alkalinity concentrations $\left(\mu \mathrm{mol} \mathrm{kg}-1\right.$ ) measured in September 2001, (b) corresponding $\Delta p \mathrm{CO}_{2}(\mathrm{ppm})$, the difference of partial pressure of ocean and atmospheric $\mathrm{pCO}_{2}$, (c) reduced alkalinity concentrations due to a reduction of $50 \%$ of the estimated alkalinity flux by (Brenner et al., 2016), and (d) $\Delta p \mathrm{CO}_{2}$ corresponding to the reduced alkalinity in (c).

and the corresponding $\Delta p \mathrm{CO}_{2}$ values would exhibit much stronger oversaturation (Fig. 1d). This simple experiment focusses only on the reduced alkalinity flux without embedding such a situation into a corresponding environment. Furthermore it ignores the seasonality of the alkalinity fluxes and the fact that DIC fluxes would vary in concert.

In this paper we investigate the variability of alkalinity generation and the efflux to the pelagic zone by means of a regional biogeochemical model. The second chapter presents methods concerning the model set-up, particularly with regard to the adaptation of the former open ocean sediment model (Heinze et al., 1999) to shelf sea conditions. In the third chapter model results are compared with observational data. In the fourth chapter we show the results of several scenarios demonstrating the sensitivity of the total model dynamics to environmental settings due to changing alkalinity fluxes. One of these scenarios picks up the thought experi- ment mentioned above. It demonstrates the strong impact of reduced alkalinity fluxes on the $p \mathrm{CO}_{2}$ (see Sect. 4.2).

\section{Methods}

The simulations were performed with the ECOHAM ecosystem model (Pätsch and Kühn, 2008) using the nesting method focussing on the central and southern North Sea (50.88 to $57.28^{\circ} \mathrm{N}, 3.42^{\circ} \mathrm{W}$ to $9.25^{\circ} \mathrm{E}$ ) (Pätsch et al., 2010). The model system includes the HAMSOM hydrodynamic model (Backhaus, 1985; Pohlmann, 1996; Pätsch et al., 2017) and the vertically resolved sediment model originally developed for the deep open ocean (Heinze et al., 1999). The latter model has been adopted to shelf sea dynamics; details are discussed below. The 3-D fields of temperature $(T)$, salinity $(S)$, advective flow, and vertical turbulent mixing coefficients 


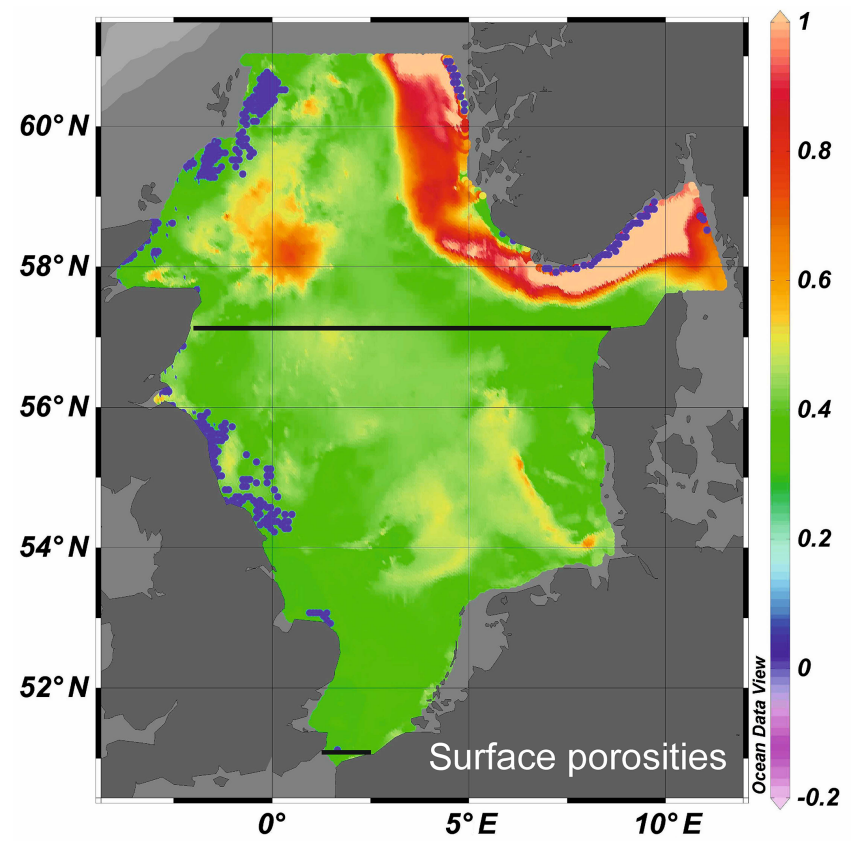

Figure 2. Porosity field calculated from grain size distribution (Bockelmann et al., 2018). Blue areas indicate rocky sediments, red areas indicate muddy sediments with low grain diameters, and green areas indicate sandy ground. The black lines indicate the model boundaries.

calculated by HAMSOM are used as forcing for ECOHAM. The time step of ECOHAM is 5 min.

\subsection{The hydrodynamic model}

The 3-D fields of temperature, salinity, advective flow, and vertical turbulent mixing coefficients calculated by the HAMSOM hydrodynamic model are used as forcing for the ECOHAM pelagic biogeochemical model. HAMSOM is a baroclinic, primitive equation model using the hydrostatic and Boussinesq approximations. The current velocities are calculated using a first-order component-upstream scheme. The horizontal is discretized on a staggered Arakawa C-grid (Arakawa and Lamb, 1977) with a resolution of $\Delta \lambda=1 / 3^{\circ}$ and $\Delta \phi=1 / 5^{\circ}$.

In a first step the model was applied to a larger area including the Northwest European Shelf $\left(15.250^{\circ} \mathrm{W}\right.$ to $14.083^{\circ} \mathrm{E}$, 47.583 to $63.983^{\circ} \mathrm{N}$ ) (Lorkowski et al., 2012). For this largedomain run sea surface elevations of the M2 semi-diurnal lunar tide were prescribed at the open boundaries (Backhaus, 1985). The corresponding results of temperature, salinity, and surface elevation were stored on the boundaries of the smaller model domain used in this study (black lines in Fig. 2). These data were used as boundary conditions for the HAMSOM hydrodynamic model implemented on the smaller domain with a vertical resolution of $5 \mathrm{~m}$ in the upper $50 \mathrm{~m}$ and increasing resolution below. The M2 tide is thus induced implicitly by the prescribed surface elevation at the boundaries. Details of the nesting procedure can be found in (Schwichtenberg, 2013).

\subsection{The pelagic biogeochemical module}

In the same way as for the hydrodynamic model in a first step, the biogeochemical model ran on the larger model domain and provided boundary conditions for the model on the smaller grid (Fig. 2).

The pelagic biogeochemical model includes four nutrients (nitrate, ammonium, phosphate, silicate), two phytoplankton groups (diatoms and flagellates), two zooplankton groups (micro- and meso-zooplankton), bacteria, two fractions of detritus (fast and slowly sinking), labile dissolved organic matter, semi-labile organic carbon, oxygen, calcite, dissolved inorganic carbon, and total alkalinity. Only for phytoplankton growth and exudation is a $Q_{10}$ value of 1.5 defined. All other processes are temperature independent. Calcite formation is performed by flagellates, only. The molar ratio of soft tissue production to calcite production is $10: 1$. Opal is built by diatoms only and the ratio of carbon to opal production is $1.74: 1$. The model differentiates between normal exudation by phytoplankton, the result of which is labile dissolved organic matter with Redfield composition corresponding to the Redfield production, and an excess exudation of semilabile organic carbon. The pelagic module is described in detail in (Lorkowski et al., 2012). For this study we included the prognostic alkalinity calculation from (Schwichtenberg, 2013). The different processes (Fi) and their influence on alkalinity are

- F01 - calcite dissolution,

- F02 - calcite formation,

- F03 - nitrification,

- F04 - uptake of nitrate,

- F05 - release of ammonium,

- F06 - uptake of ammonium,

- F07 - atmospheric deposition of ammonium,

- F08 - atmospheric deposition of nitrate,

- F09 - uptake of phosphate, and

- F10 - release of phosphate.

These fluxes determine the change in alkalinity:

$$
\begin{gathered}
\frac{\partial \mathrm{TA}}{\partial t}=2(\mathrm{~F} 01-\mathrm{F} 02-\mathrm{F} 03)+\mathrm{F} 04+\mathrm{F} 05 \\
-\mathrm{F} 06+\mathrm{F} 07-\mathrm{F} 08+\mathrm{F} 09-\mathrm{F} 10 .
\end{gathered}
$$

Together with the dynamic sediment module which exchanges TA and DIC with the pelagic system, it was possible to simulate the full carbonate system prognostically. 


\subsection{The sediment module}

\subsubsection{The open ocean sediment model}

The original sediment model was developed by (Heinze et al., 1999) for the global ocean. This model simulated accumulation, degradation, and burial of particulate organic and shell material and a diffusive porewater exchange with the overlying ocean. It was applied mainly for the deep ocean with its low amounts of incoming particulate matter compared to the shallow shelf sea export. The corresponding timescales of flux variations were rather large (annual to decadal) and showed no seasonal signal. This model included the solid components particulate organic matter (POM), calcite, opal, and silt exported from the pelagic and the dissolved components phosphate $\left(\mathrm{PO}_{4}\right)$, dissolved inorganic carbon (DIC), alkalinity (TA), silicate $\left(\mathrm{Si}(\mathrm{OH})_{4}\right)$, nitrate $\left(\mathrm{NO}_{3}\right)$, oxygen $\left(\mathrm{O}_{2}\right)$, and dinitrogen $\left(\mathrm{N}_{2}\right)$.

\subsubsection{The vertical resolution}

The upper $156 \mathrm{~mm}$ of the sediment are resolved by 12 layers with increasing thickness $(2-24 \mathrm{~mm})$. Below the deepest layer a dimensionless burial layer is implemented.

\subsubsection{New components}

As the pelagic model delivers sinking particulate material with freely varying stoichiometry, we differentiated benthic POM into the state variables particulate organic carbon (POC), nitrogen (PON), and phosphorus (POP). Additionally we added ammonium $\left(\mathrm{NH}_{4}\right)$ as a product of the incomplete aerobic degradation which can be oxidized by nitrification when oxygen is available (Paulmier et al., 2009). The release of ammonium by aerobic degradation increases alkalinity. This ammonium can be nitrified locally, which in turn leads to the combined effect of an alkalinity decrease. Still it is possible that this ammonium is released or oxidized elsewhere. Nitrite is not explicitly included. The model combines the effect of sulfate reduction and reoxidation of reduced sulfate compounds as net sulfate reduction (i.e. sulfate reduction minus reoxidation). The different reaction equations including the alkalinity generation are listed in the Appendix.

\subsubsection{Varying porosity}

The effectivity of several sediment reactions depends on the porosity, i.e. the portion of porewater in a given sediment volume. While the global ocean sediment model was implemented with a horizontally uniform porosity of 0.85 (Heinze et al., 1999), in the presented shelf application varying porosities were taken into account. The main parts of the North Sea sediments consist of sand, but there are also muddy areas, and even rocky areas exist. The different sediment classes are defined by the composition of grains with different diameters. A North Sea wide map of such grain compositions was taken from Bockelmann et al. (2018). As the sediment model uses porosity values $(P)$, the different grain size distributions have to be mapped to porosity values. We used the median grain size (D50) to calculate the porosity (Walter Puls, personal communication, 2015):

$$
\begin{aligned}
& P_{\text {surf }}=\min \left(1, \max \left(0.3,0.2603 \cdot 1.20325^{D 50}\right)\right), \\
& D 50=-\log _{2} d,
\end{aligned}
$$

where $d$ is the grain diameter in millimetres.

The resulting porosity values $P_{\text {surf }}$ fall in the range [0.3,1]. Only for rocky sediments is the porosity defined as zero (Fig. 2). According to (Heinze et al., 1999) porosities $P(z)$ in deeper layers were defined in relation to the top layer:

$P(z)=P_{\text {surf }} \cdot e^{k_{0} \cdot z(m)}$.

For $k_{0}=2.12$ and $P_{\text {surf }}=0.3$ the deepest layer at $z_{k=12}=$ $-0.144 \mathrm{~m}$ obtains a value of $P\left(z_{k=12}\right)=0.22$.

\subsubsection{Turnover rates}

The reaction equations and the chosen stoichiometries are described in detail in the Appendix. These equations use turnover rates which were modified in comparison to the original open ocean sediment model (see Table 1). One typical feature for the North Sea is that particulate organic carbon fluxes and DIC effluxes are nearly balanced (de Haas et al., 2002). To achieve this we had to increase the rates. Another criterion to alter the rates was to adapt the seasonality of oxygen fluxes into the sediment to observations (Friedrich et al., 2015).

\subsubsection{Temperature dependency}

As the shallow water column in the North Sea exhibits strong seasonal temperature variations $\left(\Delta T>15^{\circ} \mathrm{C}\right)$, a temperature dependency of both the turnover rates (see Appendix) and the vertical diffusion was implemented.

A $Q_{10}$ value of 1.2 for aerobic degradation, denitrification, nitrification, sulfate reduction and the dissolution of calcite and opal was chosen (see Appendix).

The vertical diffusion coefficient for all porewater tracers in the original open ocean model was constant $(\mathrm{d} v=$ $\left.10^{-9} \frac{\mathrm{m}^{2}}{\mathrm{~s}}\right)$. In the shelf model the coefficients were defined as temperature $(T)$ and porosity $(P)$ dependent (Gypens et al., 2008):

$\mathrm{d} v= \begin{cases}\left(d_{0}+a \cdot T\right) \cdot P & P<0.4 \\ \left(d_{0}+a \cdot T\right) \cdot P^{2} & P \geq 0.4 .\end{cases}$

The parameters $d_{0}$ and $a$ are defined in (Gypens et al., 2008) (their Table 2) for different groups of porewater tracers: the lowest coefficient is defined for phosphate $\left(\mathrm{d} v_{\text {pho }}\left(T_{10}\right)=5.4 \cdot P \cdot 10^{-10} \frac{\mathrm{m}^{2}}{\mathrm{~s}}\right)$; a medium coefficient $\left(\mathrm{d} v_{\text {tra }}\left(T_{10}\right)=1.4 \cdot P \cdot 10^{-9} \frac{\mathrm{m}^{2}}{\mathrm{~s}}\right)$ is valid for the biogeochemical tracers DIC, nitrate, ammonium, alkalinity, and silicate. 
Table 1. Comparison of open ocean (Heinze et al., 1999) and shelf (this study) turnover rates.

\begin{tabular}{llllll}
\hline Process & Turnover rates & Open ocean & Shelf & Unit & Eq. no. \\
\hline aerobic degradation & $\mathrm{r} 1$ & $1.160 \cdot 10^{-13}$ & $2.000 \cdot 10^{-10}$ & $\frac{\mathrm{m}^{3}}{\mathrm{mmol}_{2} \cdot \mathrm{s}}$ & (A3) \\
denitrification & $\mathrm{r} 2$ & $1.157 \cdot 10^{-7}$ & $1.736 \cdot 10^{-3}$ & $\frac{1}{\mathrm{~s}}$ & (A4) \\
sulfate reduction & $\mathrm{r} 3$ & $1.157 \cdot 10^{-9}$ & $3.472 \cdot 10^{-9}$ & $\frac{1}{\mathrm{~s}}$ & (A5) \\
calcite dissolution & $\mathrm{r} 4$ & $1.000 \cdot 10^{-13}$ & $1.000 \cdot 10^{-8}$ & $\frac{\mathrm{m}^{3}}{\mathrm{mmol} \mathrm{CO}_{3}^{2-} \cdot \mathrm{s}}$ & (A6) \\
opal dissolution & $\mathrm{r} 5$ & $1.000 \cdot 10^{-12}$ & $1.000 \cdot 10^{-11}$ & $\frac{\mathrm{m}^{3}}{\mathrm{mmol} \mathrm{SiO}_{2} \cdot \mathrm{s}}$ & (A7) \\
nitrification & $\mathrm{r} 6$ & & $1.157 \cdot 10^{-4}$ & $\frac{1}{\mathrm{~s}}$ & (A8) \\
\hline
\end{tabular}

The highest coefficient was defined for the gases oxygen and dinitrogen $\left(\mathrm{d} v_{\text {nit }}\left(T_{10}\right)=1.6 \cdot P \cdot 10^{-9} \frac{\mathrm{m}^{2}}{\mathrm{~s}}\right)$, all at $T_{10}=10^{\circ} \mathrm{C}$ and a porosity $P<0.4$, which is typical for sandy ground. In order to take into account advective exchange of porewater with the pelagic system, the coefficients for the uppermost layer were increased by a factor of 10 . This factor was determined by several sensitivity runs to balance the exchange between the sediment and the pelagic. An upper constraint for this factor was the limitation of the aerobic zone to the upper $1 \mathrm{~cm}$ of the sediment. The same factor is used by (Neumann et al., 2017) to switch between diffusive and advective nitrate exchange between sediment and pelagic in the German Bight. The temperature of the sediment was defined as the temperature of the lowest pelagic layer.

The vertical diffusion coefficient for DIC compares well with the corresponding coefficient given by (Burdige and Komada, 2013) (their Table 3) for $T=5^{\circ} \mathrm{C}$ and $P=0.36$.

\subsection{External data}

The meteorological forcing (Kalnay et al., 1996) and the river loads of carbon, alkalinity, nutrients, and organic compounds have been implemented according to (Lorkowski et al., 2012). To treat these tracers more realistically in this study, daily freshwater discharge of the rivers was also used (Pätsch et al., 2016). In this way the input of tracers from the rivers $\left(\mathrm{mmol} \mathrm{d}^{-1}\right)$ can be an effective source or sink depending on the concentrations of the tracers in the river water. For 2011 the total $\mathrm{N}$ river input was $34.4 \mathrm{Gmol} \mathrm{N} \mathrm{yr}^{-1}$.

The calculated shortwave incoming radiation has been reduced by $10 \%$ as it has been shown that the sea surface temperature (SST) would otherwise be overestimated (compare Fig. 3 in Lorkowski et al., 2012).

The atmospheric nitrogen deposition was derived following (Große et al., 2016), using annual data from the EMEP (cooperative programme for monitoring and evaluation of the long-range transmissions of air pollutants in Europe) model. As our simulation period exceeds the period of data available from EMEP, a long-term trend according to (Schöpp et al., 2003) was applied in addition. Atmospheric deposition is im- plemented as inputs of nitrate and ammonium. For 2011 the

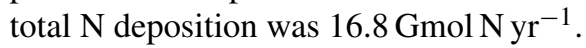

\subsection{The experiments}

For each experiment described below the biogeochemical simulation in the central and southern North Sea area was spun up over 20 years repeating the year 2000 until all processes were in equilibrium and did not change from year to year. After this procedure the years 2000 to 2014 were simulated consecutively.

Different experiments or scenarios were performed.

- The reference run with the new sediment module provides a basis with realistic boundary conditions and horizontally varying porosities.

- In order to reproduce a situation without anthropogenic influence, we reduced the inorganic and organic river input of nitrogen and phosphorus to $10 \%$ of the reference run. Additionally the atmospheric deposition of nitrogen was reduced to $28 \%$. This run more or less reproduced the "pristine conditions" (Serna et al., 2010) established.

- To analyse the impact of the new sediment module on the pelagic system, we compare the results of the reference run with results of the "plate run" scenario. In this scenario a simple sediment module was used, which collects, remineralizes, and releases the sunken particulate organic material on a 2-D plate (Pätsch and Kühn, 2008).

- In the reference run horizontally varying porosities were used $\left(P_{\min }=0.3, P_{\max }=0.51\right)$. To study the influence of this feature we conducted two additional model runs with basin-wide uniform porosities: one with the minimum porosity $P_{\min }$ and one with the maximum porosity $P_{\max }$. 


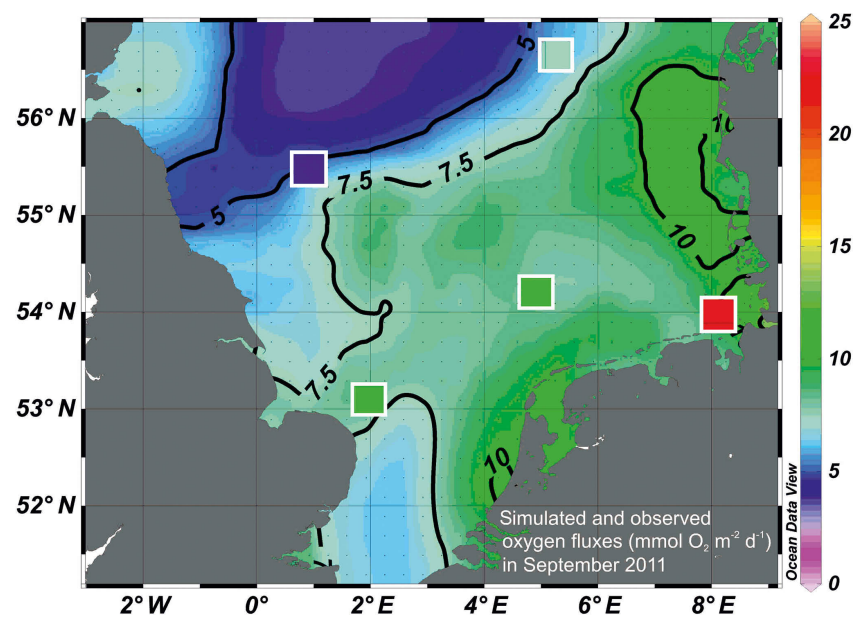

Figure 3. Simulated and observed oxygen fluxes $\left(\mathrm{mmol} \mathrm{O}_{2} \mathrm{~m}^{-2} \mathrm{~d}^{-1}\right)$ for September 2011. The observations by (Brenner et al., 2016) are indicated by the coloured rectangles.

\subsection{Error estimates}

To compare simulated results with observations, a normalized error estimate was conducted. We used the following formula:

$\mathrm{rms}=\frac{\sqrt{\sum_{i=1}^{n}\left(\mathrm{obs}_{i}-\operatorname{sim}_{i}\right)^{2}}}{\sum_{i=1}^{n} \frac{\mathrm{obs}_{i}+\operatorname{sim}_{i}}{2}}$,

where $n$ are the numbers of observations, and obs ${ }_{i}$ and $\operatorname{sim}_{i}$ are the corresponding values of the observations and simulations taken from the same location. As simulation results we used the corresponding monthly means.

\section{Comparison with observations}

To get confidence in the adapted sediment model, we compared simulated and observed fluxes between sediment and pelagic. Additionally, simulated porewater profiles were compared with observed profiles.

\subsection{Oxygen fluxes}

(Brenner et al., 2016) measured the total oxygen consumption of sediment cores which can be compared with simulated oxygen fluxes into the sediment. The corresponding available data and their positions are shown in Fig. 3 (rectangles). The underlying map of simulated oxygen fluxes at the time when observations were taken shows reasonable values $(\mathrm{rms}=0.312)$. Only in the German Bight does the model underestimate the measurements. An explanation for this effect is that particulate organics (POM) imported by the rivers are considered as slowly sinking detritus. As a consequence the horizontal export of POM out of the German Bight is over-
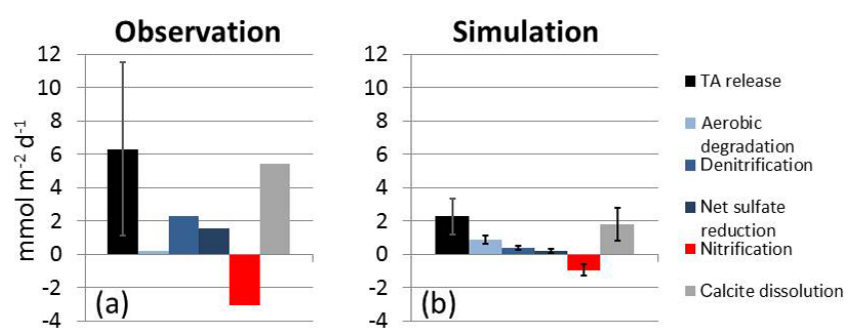

Figure 4. (a) Mean observed alkalinity flux for the southern North Sea in September 2011. Additionally the derived mean alkalinity generation due to aerobic degradation, dentrification, net sulfate reduction, and calcite dissolution is shown. A sink for alkalinity is nitrification. All fluxes in mmol m${ }^{-2} \mathrm{~d}^{-1}$ (Brenner et al., 2016). (b) Simulated alkalinity flux for the southern North Sea in September 2011. Additionally the alkalinity generation and reduction due to aerobic degradation, dentrification, net sulfate reduction, nitrification, and calcite dissolution are shown. The error bars indicate the spatial standard deviation.

estimated and the local flux into the sediment is underestimated.

\subsection{Alkalinity fluxes}

Figure 4 shows the comparison of field-wide averaged alkalinity effluxes and the contributions from aerobic degradation, denitrification, net sulfate reduction, nitrification, and calcite dissolution from observations in September 2011 (Brenner et al., 2016) and from our model results for September 2011. For the observational data only the spatial standard deviation of alkalinity efflux is given (see the error bar in Fig. 4a). The temporal standard deviation of the simulated daily values within September 2011 is for all fluxes very small and not shown $\left(<0.003 \mathrm{mmol} \mathrm{m}^{-2} \mathrm{~d}^{-1}\right)$. The spatial standard deviations of the simulated September fluxes are shown as error bars in Fig. 4b. Even though the simulated efflux lies within the high spatial variability of the observed alkalinity efflux, the model rather underestimates all contributions. Only the simulated contribution from aerobic degradation is larger than the corresponding observation. The main deviation can be attributed to the low simulated calcite dissolution within the sediment. The RMSE of alkalinity generation is 0.655 .

In comparison to other models (Ridgwell et al., 2007; Lorkowski et al., 2012), the ratio of simulated particulate organic carbon to particulate inorganic carbon (POC: $\mathrm{PIC}$ ) is relatively low, meaning high calcite production in relation to organic carbon production. Nonetheless our model still leads to an underestimation of the calcite dissolution in the sediment compared to the analysis of (Brenner et al., 2016). Calcite production is reported to occur sporadically, which in turn would characterize the observations not necessarily representative for the southern and central North Sea. 

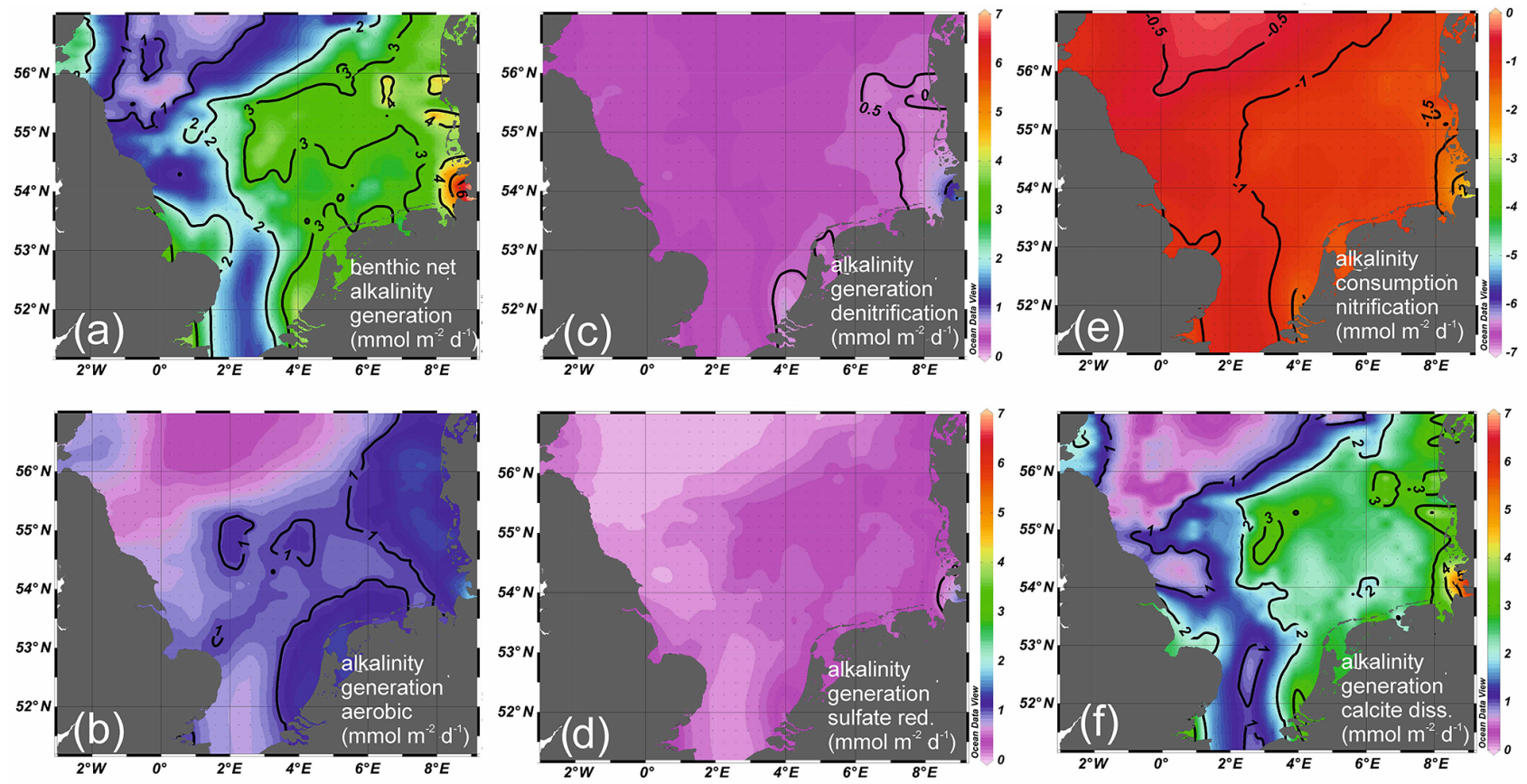

Figure 5. (a) Simulated net alkalinity generation and corresponding sources and sinks due to (b) aerobic degradation, (c) denitrification, (d) net sulfate reduction, (e) nitrification, and (f) calcite dissolution in September 2011. All fluxes in mmol $\mathrm{m}^{-2} \mathrm{~d}^{-1}$. The scale of (a)-(d) is identical.

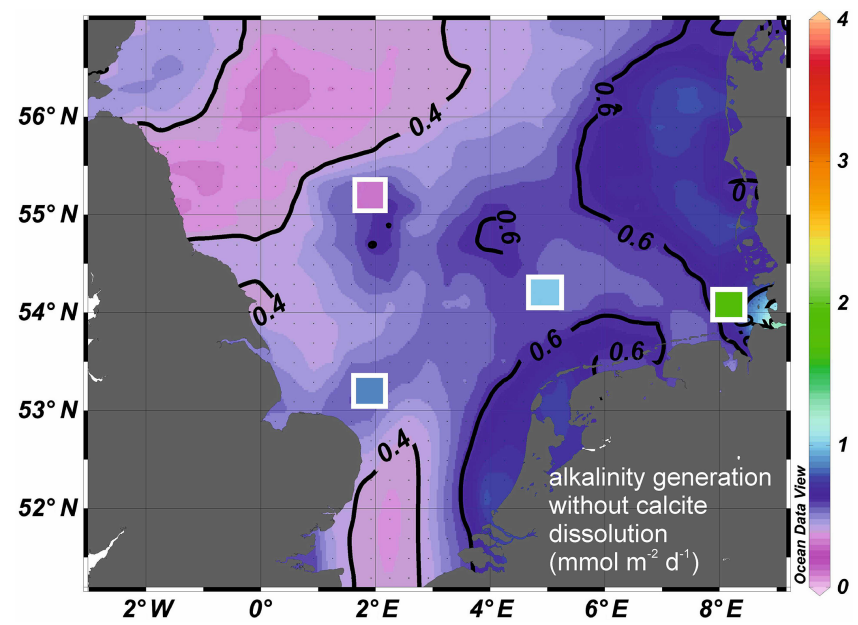

Figure 6. Simulated and observed alkalinity generation $\left(\mathrm{mmol} \mathrm{m}{ }^{-2} \mathrm{~d}^{-1}\right)$ without calcite dissolution for September 2011. The observations are indicated by the coloured rectangles.

Figure 5 shows the corresponding simulated alkalinity fluxes to the pelagic system for September 2011. The alkalinity efflux is strongest in the German Bight near the mouth of the River Elbe. The flux decreases with distance from the continental coast. Elevated values can be seen off the Danish coast. Similar features can be observed for the contributors aerobic degradation, denitrification, net sulfate reduction, and calcite dissolution. The distribution of the negative fluxes due to nitrification also shows elevated values in the German Bight.

When ignoring the sedimentary calcite dissolution in both the simulation and the observed data, the remaining alkalinity generation compares better with the observations (Fig. 6). The RMSE reduces to 0.447. Only in the inner German Bight does the simulated flux appear far too low. An explanation for this effect is the same as for oxygen fluxes: the export of POM out of the German Bight is overestimated and thus local remineralization underestimated.

\subsection{Profiles}

During cruise He-308 in May 2009 several sediment cores in the German Exclusive Economic Zone (EEZ) were taken and investigated. The nitrate data are published by (Neumann et al., 2017), and all data are archived in https://doi. pangaea.de/10.1594/PANGAEA.872715,2017. We compare our results of the reference run with observed data of oxygen, nitrate, phosphate, and ammonium (Fig. 7). To understand the model sensitivity, the corresponding profiles of the "pristine conditions" run are also shown. The position of the chosen core is between the German coast and the island of Helgoland $\left(54^{\circ} 5^{\prime} \mathrm{N}, 8^{\circ} \mathrm{E}\right)$. This area is strongly affected by high nutrient loads from the continental rivers and high atmospheric nitrogen deposition (Pätsch et al., 2010) resulting in significant differences in the simulated porewater concentrations of the reference run and the "pristine conditions" scenario (solid and dashed black lines). The simulated oxy- 

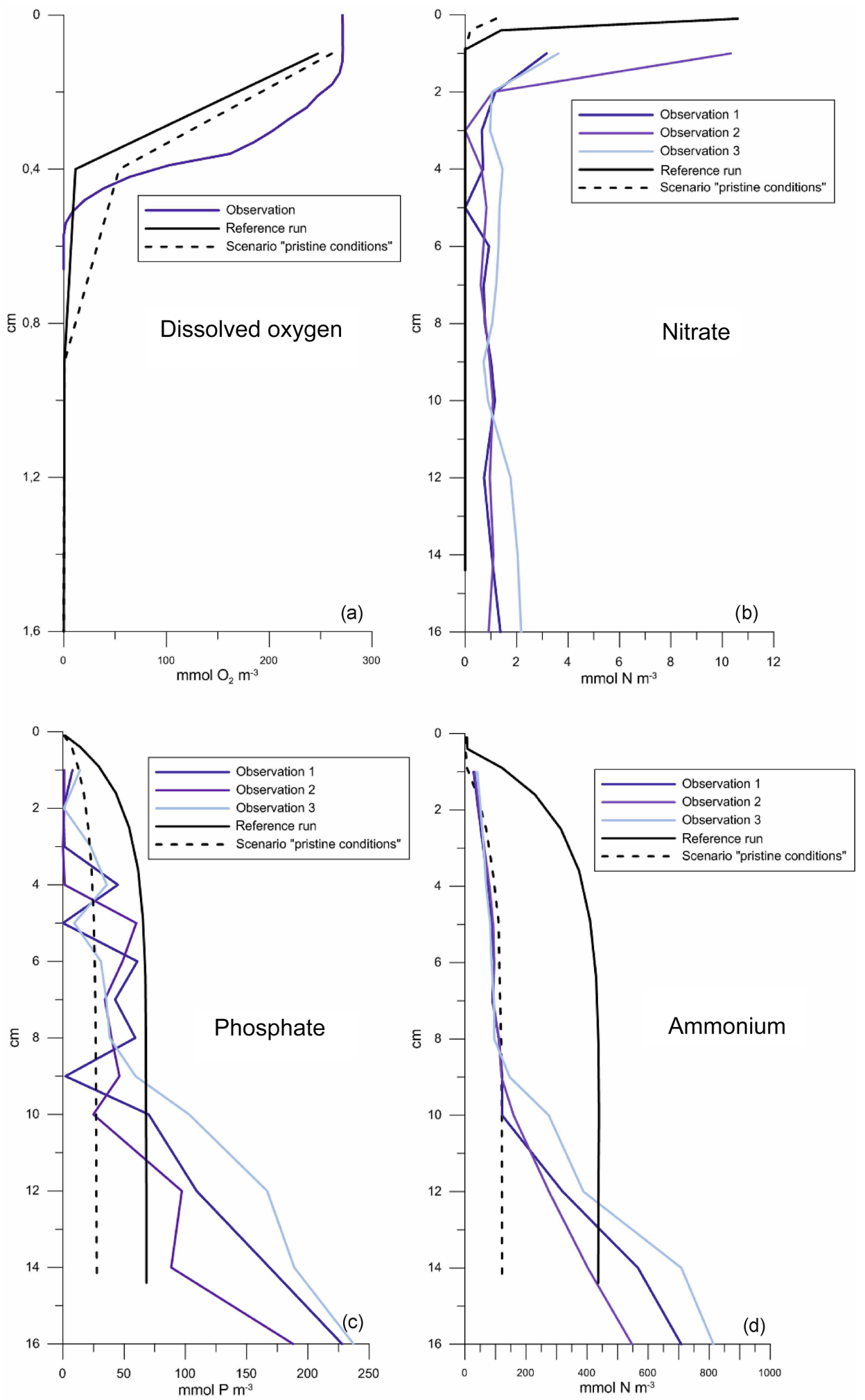

Figure 7. Profiles of porewater concentrations of (a) oxygen, (b) nitrate, (c) phosphate and (d) ammonium at $54^{\circ} 5^{\prime} \mathrm{N}, 8^{\circ} \mathrm{E}$ in May 2009. Nitrate data were published by (Neumann et al., 2017). The black solid line indicates the reference run, the dashed black line represents the results of the "pristine conditions" scenario and the different blue lines are derived from observations during cruise He-308. In (b)(d) repeated observational profiles are shown. Note the different profile depths. 
gen penetration depth (concentration $<10 \mathrm{mmol} \mathrm{O}_{2} \mathrm{~m}^{-3}$ ) is about $0.5 \mathrm{~cm}$, which fits to the observations (Fig. 7a). It is about $0.8 \mathrm{~cm}$ in the "pristine conditions" scenario. In the upper $0.4 \mathrm{~cm}$ the model underestimates in both scenarios the observed oxygen concentrations. Figure $7 \mathrm{~b}$ shows the profiles of observed $\mathrm{NO}_{x}$ including nitrate and nitrite and the profiles of simulated nitrate. This seems to be a proper comparison as observed nitrite concentrations are low $\left(<0.8 \mathrm{mmol} \mathrm{N} \mathrm{m}^{-3}\right.$, not shown). Observed $\mathrm{NO}_{x}$ concentrations are detectable only in the upper $2 \mathrm{~cm}$. Due to uncalibrated measurements deeper values appear discriminable from zero concentration, but they should be interpreted as zero concentration (personal communication, Andreas Neumann). The simulated concentrations (reference run) reach very low values already at $1 \mathrm{~cm}$ depth, and the "pristine conditions" scenario shows very low concentrations already at $0.5 \mathrm{~cm}$ depth. Observed phosphate concentrations in Fig. 7c indicate two mixing regimes: in the upper $9 \mathrm{~cm}$ the sediment core shows concentrations slightly increasing with depth; below a stronger gradient can be seen. The upper part appears well mixed, while in the lower part mixing decreases. This effect might be caused by bioturbation and bioirrigation in the upper $9 \mathrm{~cm}$. As the latter processes are not included in the model, we got a more homogenous picture of the phosphate profiles. The model (reference run) overestimates the observational values in the upper part, while it underestimates them in the lower part. A similar pattern can be seen for ammonium (Fig. 7d), where again the observational concentrations indicate an upper and a lower mixing zone. The simulated values increase between the surface and the $5 \mathrm{~cm}$ horizon; below they are more or less constant. The values of the reference run are too high in the upper $13 \mathrm{~cm}$. These high simulated ammonium values might be caused by neglecting the process of anammox in the model. This process transforms reactive nitrogen compounds (ammonium and nitrite) into inert molecular nitrogen. Similar high ammonium concentrations can be found in (Luff and Moll , 2004) within their Fig. 9.

\section{Results}

\subsection{Temporal variations}

The temporal development of monthly alkalinity effluxes (2000-2014) without calcite dissolution of a near-coastal station $\left(54^{\circ} \mathrm{N}, 8^{\circ} \mathrm{E}\right)$ shows an overall decreasing trend (Fig. 8). To understand this feature the sources of alkalinity generation and the annual loads of nitrate by the River Elbe (Radach and Pätsch, 2007; Pätsch et al., 2016) in the German Bight $\left(53.9^{\circ} \mathrm{N}, 8.9^{\circ} \mathrm{E}\right)$ are shown (see Fig. 1a). Calcite dissolution is very variable and exhibits a decrease over the simulation period. Because of its high variability, which would overwrite the nitrogen-related signals, calcite dissolution is not shown.
Aerobic degradation with a distinct annual cycle appears quite constant over the years. Sulfate reduction is more or less constant, while nitrification (as a negative contribution) shows a positive trend in contrast to the negative trend of denitrification. The dark blue line represents the nitrate discharge of the nearby River Elbe. With strong seasonal peaks it exhibits a negative trend which can explain a similar trend in denitrification.

Strong nitrate discharge events are followed some months later by local maxima in denitrification. The lag correlation of these two time series showed the highest and significant coefficients $(r>0.65)$ for 2-3 months' time shift. For the years 2003 and 2011 this time lag is clearly visible. Over several successional winter months in 2007/2008 high nitrate loads led to strong denitrification in 2008. In all these years the TA efflux was elevated. This is reflected by high lag correlations $(r>0.63)$ of the Elbe nitrate time series and TA generation for a lag of 4-5 months.

\subsection{Alkalinity generation and $\mathrm{pCO}_{2}$}

As already demonstrated in the thought experiment in the introduction, the alkalinity release from the sediment has a significant impact on the carbonate system and thus on the $\Delta p \mathrm{CO}_{2}$ regulating the exchange of $\mathrm{CO}_{2}$ between the atmosphere and the sea.

Using the 2000-2014 simulated time series (reference run), we analysed the cumulative alkalinity efflux out of the sediment from the beginning of the year of 2011 to midSeptember 2011 (Fig. 9a). Near the Danish coast we found a flux of about $1000 \mathrm{mmol} \mathrm{m}^{-2}$ for this period. For the inner German Bight even higher values can be found. These maxima result in corresponding areas of strong undersaturation in respect of $\triangle p \mathrm{CO}_{2}$ for September (Fig. 9b). The interior and the north-western part are slightly oversaturated. Nearcoastal areas of strong undersaturation are also affected by high primary production, which in addition to the alkalinity efflux from the sediment lowers the $\Delta p \mathrm{CO}_{2}$. This could be shown in an additional experiment where these effluxes were artificially switched off.

Figure 9c shows the alkalinity flux of the "pristine conditions" run until mid-September. The flux reduction (compare with Fig. 9a) is strongest $(\approx 20 \%)$ in areas where the generation of alkalinity was strongest. Areas of oversaturation of $\Delta p \mathrm{CO}_{2}$ (Fig. 9d) increase and especially in the shallow areas with high sediment impact the previously undersaturated situations turn into oversaturation (or light undersaturation). Because of the distance to the rivers, the situation is more or less unchanged in the central part.

As the effect of alkalinity generation until mid-September on the mean September $\Delta p \mathrm{CO}_{2}$ distributions is not straightforward, we analysed additionally the horizontal distributions of the temporal cumulated air-sea flux of $\mathrm{CO}_{2}$ until mid-September (not shown). Similarly to the $\Delta p \mathrm{CO}_{2}$ distributions, in September more or less no differences between 


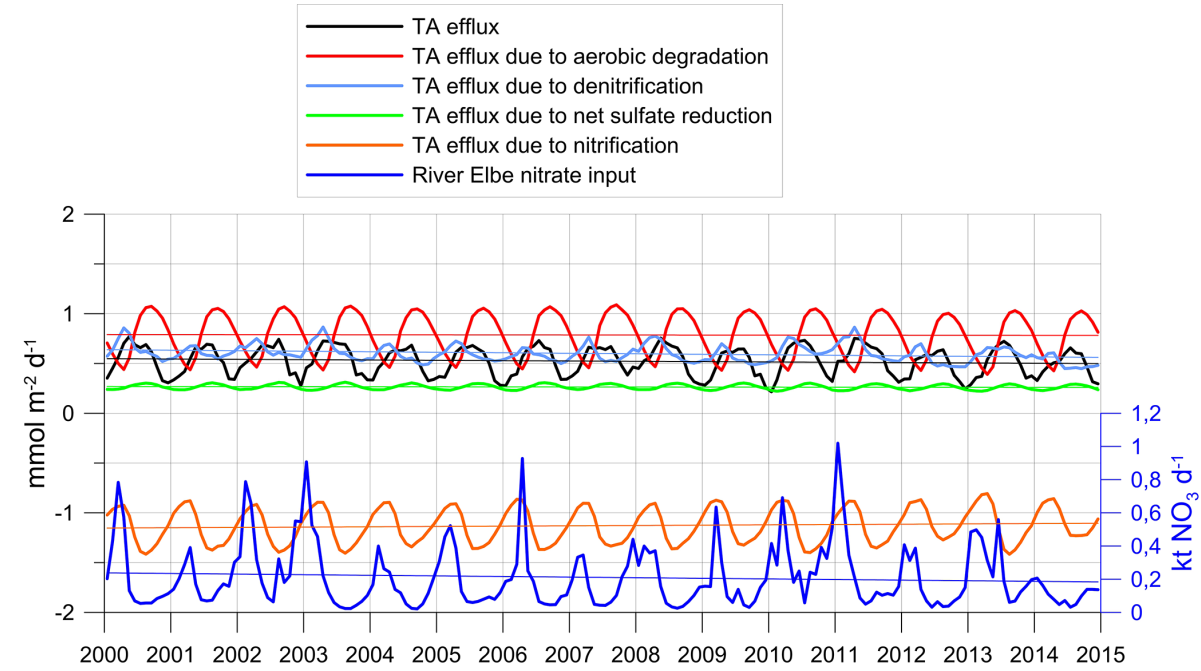

Figure 8. Simulated monthly values of alkalinity efflux $\left(\mathrm{mmol} \mathrm{m}^{-2} \mathrm{~d}^{-1}\right)$ from the sediment without calcite dissolution at $54^{\circ} \mathrm{N}, 8^{\circ} \mathrm{E}$, the corresponding sources and sinks due to aerobic degradation, denitrification, net sulfate reduction, nitrification and the annual loads of nitrate ( $\mathrm{kt} \mathrm{NO}_{3} \mathrm{~d}^{-1}$ )from the River Elbe (Radach and Pätsch, 2007; Pätsch et al., 2016). Note: nitrification has a negative contribution to the alkalinity generation.
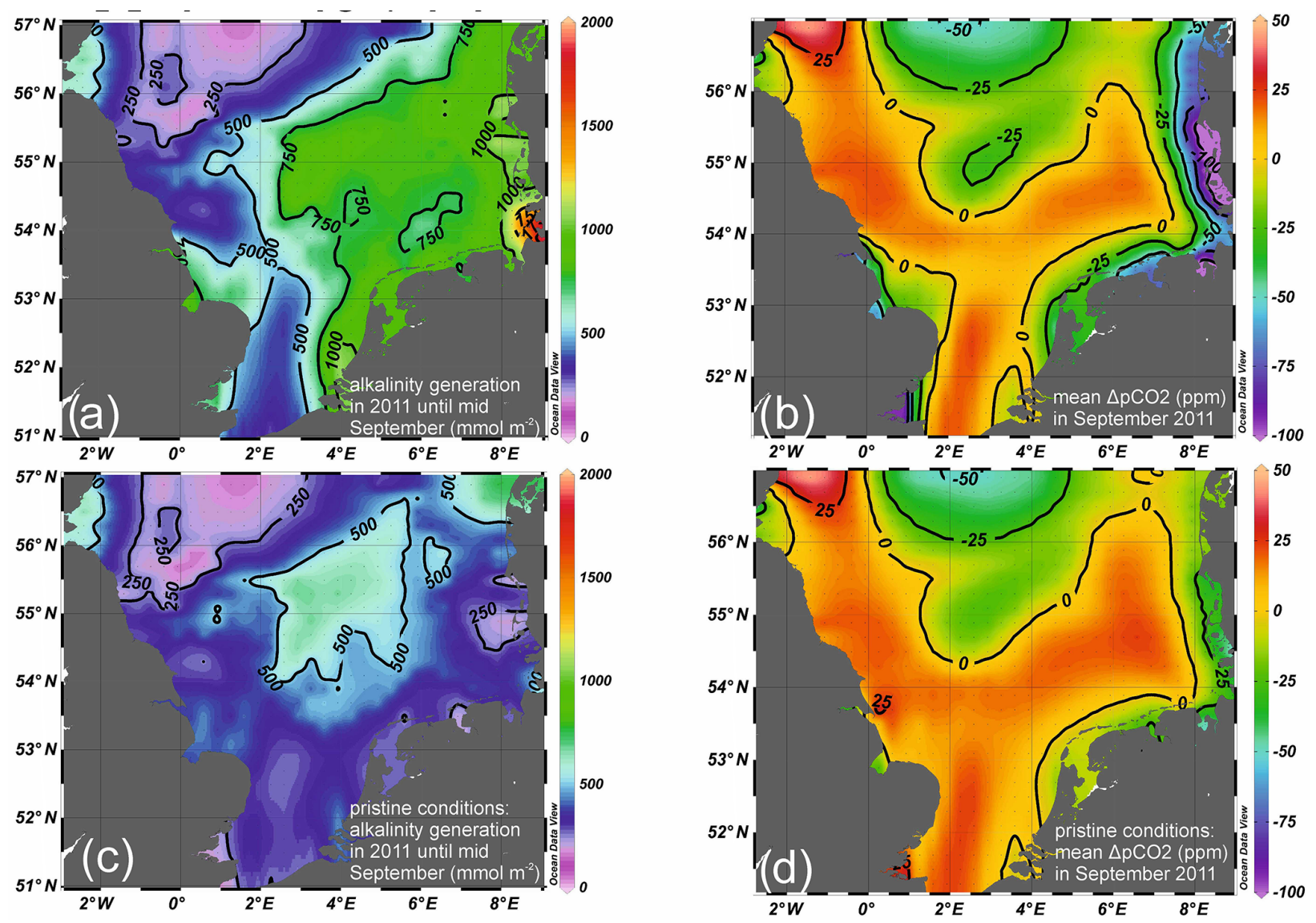

Figure 9. (a) Simulated cumulative alkalinity generation in 2011 until mid-September $\left(\mathrm{mmol} \mathrm{m}^{-2}\right)$ for the reference run, (b) the corresponding $\Delta p \mathrm{CO}_{2}(\mathrm{ppm})$ in September, (c) cumulative alkalinity generation until mid-September with reduced river input (10\%) and only $28 \%$ atmospheric nitrogen deposition ("pristine conditions"), and (d) $\Delta p \mathrm{CO}_{2}$ in September ("pristine conditions"). 


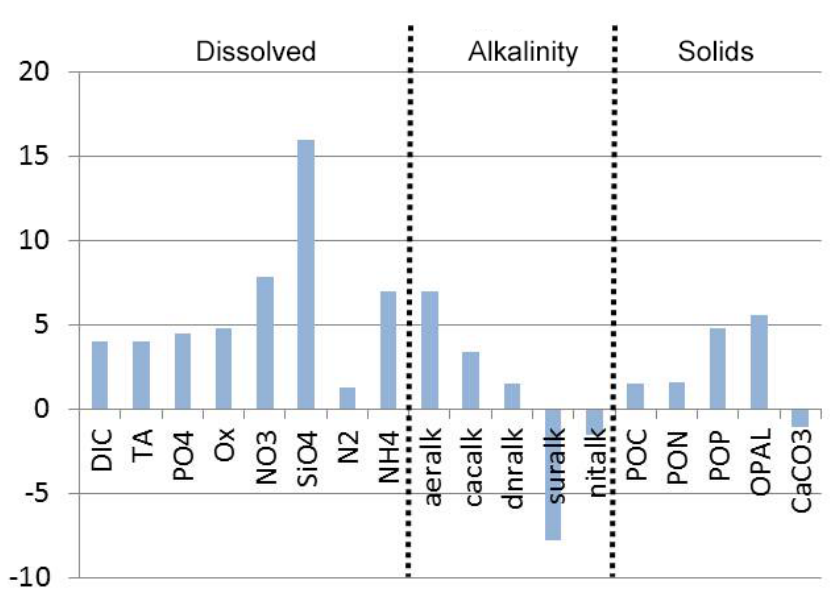

Figure 10. Deviations between the "high" and "low" porosity runs. Shown is the relative change in annual fluxes (\%) between the sediment and the pelagic for a station at $54^{\circ} 5^{\prime} \mathrm{N}, 8^{\circ} \mathrm{E}$ in 2011 . DIC, TA, $\mathrm{PO}_{4}, \mathrm{SiO}_{4}, \mathrm{~N}_{2}$, and $\mathrm{NH}_{4}$ indicate the diffusive fluxes of dissolved matter from the sediment into the pelagic. Ox and $\mathrm{NO}_{3}$ are corresponding fluxes from the pelagic into the sediment. aeralk, cacalk, dnralk, suralk, and nitalk indicate the partitioning of the alkalinity flux according to its sources aerobic degradation, calcite dissolution, denitrification, sulfate reduction, and nitrification, respectively. The fluxes of solids from the pelagic into the sediment are POC, PON, POP, OPAL, and $\mathrm{CaCO}_{3}$.

the reference run and the "pristine conditions" run can be seen in the deeper water of the northern areas. Small differences can be found in the southern open sea areas, but high differences occur near the continental coast where the differences due to altered primary production also exist.

\subsection{Sensitivity on different porosities}

To investigate the effect of spatially varying porosities we conducted two additional simulations which were spun up separately: one with a basin-wide uniform porosity with the minimum value of the reference run except for rocks $\left(P_{\min }=\right.$ $0.3)$ and one with the maximum value $\left(P_{\max }=0.51\right)$. For the different annual fluxes between the sediment and the pelagic at $54^{\circ} 5^{\prime} \mathrm{N}, 8^{\circ} \mathrm{E}$ the relative deviations (\%) of these two runs are analysed for 2011 (Fig. 10).

Switching over from the $P_{\min }$ run to the $P_{\max }$ run, the diffusive flux of DIC, alkalinity, and phosphate out of the porewater of the sediment increases by about $4 \%$. The flux of silicate from the sediment increases by $16 \%$. Also, the import of oxygen and nitrate increases. This overall increase is astonishing as the effective diffusivity decreases when the porosity passes over the limit of 0.4 (see Sect. 2.3.6). Of interest are also the deviations of the five contributors to the alkalinity flux, i.e. the alkalinity flux due to the aerobic degradation $(+7 \%)$, the calcite dissolution $(+3.4 \%)$, the denitrification $(+1.5 \%)$, the sulfate reduction $(-7.8 \%)$, and the (negative) nitrification $(-0.5 \%)$. Sulfate reduction decreases as the amount of POC reaching the deeper sediment layers decreases due to the enhanced aerobic remineralization.

Due to positive feedback mechanisms on the nutrients in the water column, the sinking fluxes of particulate organic matter (POC, PON, POP) increase. The largest increase in solids entering the sediment can be found for opal $(+5.6 \%)$, corresponding to the large silicate efflux from the sediment into the pelagic. Calcite export slightly decreases as the silicon shell building diatoms are favoured by the increased silicate availability.

To understand this counterintuitive dynamics we compared the model results of the high porosity run with the low porosity run in the first and second spin-up years. At the beginning of the first spin-up year all conditions are the same. Until spring the flux of oxygen into the sediment was lower in the high porosity run because there the effective diffusivity was lower than in the low porosity run. The lower oxygen content in the high porosity run stimulated the benthic anaerobic processes. At the end of the first year this resulted in a higher efflux of ammonium $(+5.8 \%)$ from the sediment in the high porosity scenario. The higher ammonium efflux of the high porosity scenario was not compensated by the higher nitrate flux into the sediment $(+1.6 \%)$. At the end of the year more DIN was in the pelagic water column in the high porosity scenario than in the low porosity scenario. In the second year this surplus of DIN stimulated higher primary production for the high porosity scenario. The corresponding enhanced particle export additionally increased the benthic-pelagic fluxes. The loss of molecular nitrogen due to enhanced denitrification was compensated by the larger ammonium efflux. These deviating dynamics are even stronger at stations with lower pelagic DIN concentrations in offshore areas.

\subsection{Comparison of the vertical resolved and plate sediment module}

In former model versions (Pätsch and Kühn, 2008; Lorkowski et al., 2012; Große et al., 2016) the sediment was represented by a two-dimensional plate without depth resolution. The sinking material was gathered and remineralized on the surface of this plate. The remineralization rates had been adjusted so that the particulate organic material from the last year was more or less dissolved and released by February/March of the following year.

The temporal development of carbon exchange between sediment and pelagic in 2011 at $54^{\circ} 5^{\prime} \mathrm{N}, 8^{\circ} \mathrm{E}$ is shown in Fig. 11a for the "plate run". The time in the year when half of the exported particulate material is returned as DIC ("half time") is indicated by the black arrow on the x-axis. For the "plate run" this is day 230.

Figure 11b shows the corresponding carbon fluxes of the reference run. While the shape of the curve representing the particulate export is similar to that of Fig. 11a, the remineralization flux shows less temporal variation. Due to the high 

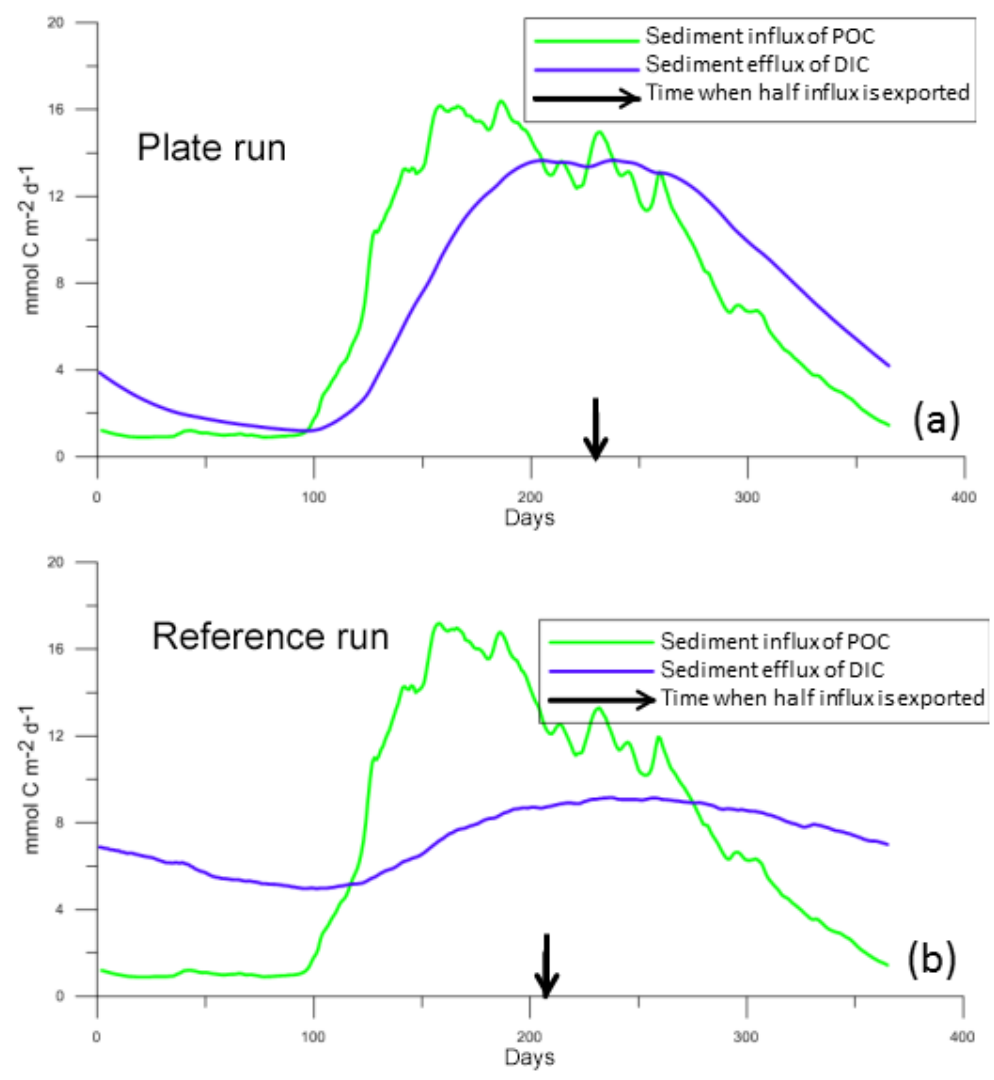

Figure 11. Temporal development of carbon fluxes between the pelagic and the sediment $\left(\mathrm{mmol} \mathrm{C} \mathrm{m}^{-2} \mathrm{~d}^{-1}\right)$ at $54^{\circ} 5^{\prime} \mathrm{N}, 8^{\circ} \mathrm{E}$ in 2011 for $(\mathbf{a})$ the "plate run" and (b) the reference run. The time in the year when half of the deposited particulate material is returned as DIC is indicated by the black arrow on the $x$-axis.

remineralization flux in winter the "half time" is reached earlier (day 207).

The different carbon remineralization rates in the sediment and the simulated concentrations of particulate organic carbon and oxygen of the reference run and the "plate run" resulted in comparable effluxes of carbon.

There are several reasons for the deviating seasonal cycle of DIC efflux. In general the less pronounced cycle is caused by

- The structure of the 3-D-sediment model in which the fastest reaction occurs in the very thin upper layer. Lower layers act more slowly.

- The fact that the remineralization fluxes do not immediately produce effluxes. In case of the 3-D-sediment model the dissolved compounds have to be transferred via diffusion into the pelagic system.

- The high concentration of POC in the 3-D sediment model: whereas in the 2-D-plate model nearly all POC is dissolved after winter, in the 3-D-sediment model a relatively high standing stock of POC still remains.

\section{Discussion}

\section{$5.1 \quad$ Nitrogen-related processes}

After calcite dissolution benthic denitrification is the second largest positive contribution to alkalinity generation (Fig. 4). Near-bottom nitrate concentration, which is correlated with near-bottom oxygen saturation, governs the direction of nitrate exchange across the pelagic-sediment interface (Neubacher et al., 2011). In case of the invasion of pelagic nitrate into the sediment, benthic denitrification is stimulated. The other source of benthic nitrate is the benthic nitrification which is driven by oxygen within the sediment. At $54^{\circ} \mathrm{N}, 8^{\circ} \mathrm{E}$, however, $86 \%$ of oxygen is consumed by aerobic degradation and only $14 \%$ by benthic nitrification. For shelf seas (Seitzinger and Giblin, 1996) estimated the local benthic denitrification rate (DNR) to be about $2 \%$ of the local primary production (PP). This estimate, of course, can be influenced by parameters like water depth, advection, and near-bottom oxygen consumption. Indeed, the evaluation of our reference run shows that the relation $r=\mathrm{DNR} / \mathrm{PP}$ was about $2 \%$ in regions with a water depth of about $30 \mathrm{~m}$ and an annual Redfield production (see Sect. 2.2) of about 
$150 \mathrm{~g} \mathrm{C} \mathrm{m}^{-2} \mathrm{yr}^{-1}$, which can be found some tens of kilometres off the mouths of the big rivers. According to our simulations $r$ is only larger than $2 \%$ near the mouth of the River Elbe. For all other regions $r$ ranges between 1.1 and $1.4 \%$.

In the case of the ammonium profile (Fig. 7d) the "pristine conditions" simulation matches the observation better than the reference run. This might have to do with the absence of the process anammox within the model which would consume ammonium under the presence of nitrite.

The comparison of the reference run and the "pristine conditions" run exhibits a deeper penetration of oxygen into the sediment for the pristine more nutrient depleted scenario (Fig. 7a). This is in accordance with the findings of (Neubacher et al., 2011), who differentiated a realistic and rich hypoxic situation, the latter with lower penetration depths.

\subsection{Sources of alkalinity}

An effective tracer of North Sea total alkalinity is the naturally occurring radium isotope ${ }^{228} \mathrm{Ra}$ (Burt et al., 2014). These authors estimated a coastal alkalinity input of $3.4-23.6 \mathrm{mmol} \mathrm{m}^{-2} \mathrm{~d}^{-1}$ into the southern North Sea $(A=$ $190.765 \mathrm{~km}^{2}$ ) in September 2011. This input was assumed to come mainly from the Wadden Sea. The amount of this input lies in the same range (Brenner et al., 2016) estimated as total input from the sediments into the pelagic southern North Sea (Fig. 4). This estimate is valid for a late summer situation and includes the large effect of calcite dissolution. For the southern North Sea calcite dissolution and production are roughly balanced on an annual basis. The estimate by (Burt et al., 2014) and the measurements by (Brenner et al., 2016) appear high in comparison to the value given by (Thomas et al., 2009), who estimated an alkalinity input from the Wadden Sea of $1 \mathrm{mmol} \mathrm{m}^{-2} \mathrm{~d}^{-1}$ into the south-eastern North Sea over the year. This value was calculated using an alkalinity budget which does not differentiate input from autochthonous sediment and from the adjacent Wadden Sea and, additionally, does not take into account calcite production and dissolution.

Together with our simulation results, the following picture can be given: the relatively high flux estimates by (Burt et al., 2014) and (Brenner et al., 2016) can be explained by the inclusion of calcite dissolution and the time in the year when measurements were taken. When calcite dissolution is excluded our annual estimate for the total model region $\left(0.4 \mathrm{mmol} \mathrm{m}^{-2} \mathrm{~d}^{-1}\right)$ can be compared with the estimate by (Thomas et al., 2009) for the south-eastern North Sea, with higher productivity than the average of the model region.

\section{Conclusions}

Even though our model may slightly underestimate benthic denitrification in the southern North Sea, it reveals this process as the largest net contribution to alkalinity generation in this area. This compares well with the estimates by (Brenner et al., 2016) when the dissolution of calcite is not taken into account, because the observational data might miss the calcite production signal which then would cancel out the effect on alkalinity. Estimates of other alkalinity fluxes like alkalinity generation in the Wadden Sea are not taken into account as their estimates appear not well constrained. A direct modelling approach of such sources of alkalinity appears necessary (Schwichtenberg, 2013), but is beyond the scope of this study.

Data availability. The grainsize data (Bockelmann et al., 2018) are stored in the "coastMap" geodatabase, a part of the marine geodata infrastructure of the Biogeochemistry department at the Helmholtz-Zentrum Geesthacht (www.hzg.de/institutes_platforms/ coastmap, Bockelmann et al., 2018). They are also archived at the World Data Center for Climate (WDCC) at DKRZ (https: //doi.org/10.1594/WDCC/coastMap_Substrate_MGS, Bockelmann et al., 2018). The profile data by Andreas Neumann are available at: https://doi.pangaea.de/10.1594/PANGAEA.872715,2017 (Neumann et al., 2017) 


\section{Appendix A}

\section{A1 Equations for solid and dissolved sediment components}

Dissolved matter: exchange with the ECOHAM pelagic ecosystem model (DIC $(i=1), \mathrm{TA}(i=2), \mathrm{PO}_{4}(i=3), \mathrm{NO}_{3}$ $\left.(i=4), \mathrm{NH}_{4}(i=5), \mathrm{N}_{2}(i=6), \mathrm{SiO}_{4}(i=7), \mathrm{O}_{2}(i=8)\right)$ :

$$
\frac{\partial \mathrm{C}_{i}}{\partial t}=\mathrm{d} v_{i} \frac{\partial^{2} \mathrm{C}_{i}}{\partial x^{2}}+\sum_{j=1}^{6} a_{i j} \cdot \frac{R_{j}}{P} .
$$

$R_{j}\left(\mathrm{mmol} \mathrm{m}^{-3} \mathrm{~s}^{-1}\right)$ are reaction terms for the dissolved matter. $P$ : porosity. $\mathrm{d} v_{i}$ are the vertical diffusion coefficients described in Sect. 2.3.6. The coefficients $a_{i j}$ are predefined as zero.

Solids: input from the ECOHAM pelagic ecosystem model.

POC, PON, POP, $\mathrm{CaCO}_{3}, \mathrm{SiO}_{2}$ (opal), silt (with predefined constant input))

$$
\frac{\partial S_{m j}}{\partial t}=D \frac{\partial\left(w S_{m j}\right)}{\partial z}-\sum_{m=1}^{6} b_{m j} \cdot \frac{R_{j}}{1-P}
$$

$w$ : vertical advection (downward). The coefficients $b_{m j}$ are predefined as zero.

\section{A2 Reaction terms $\boldsymbol{R}_{j}$}

- Degradation of POM

- $\mathrm{AD}$ aerobic degradation $(j=1)$

$$
R_{\mathrm{POC}}^{\mathrm{AD}}=r_{1} \cdot T_{\mathrm{fac}}(T) \cdot[\mathrm{POC}] \cdot\left[\mathrm{O}_{2}\right]
$$

With turnover rate $r_{1}$ (see Table 1) and resetting the indices of the matrix $a_{i j}$ in Eq. (A1) to $a_{11}=$ $1, a_{21}=\mathrm{N} / \mathrm{P}, a_{31}=\mathrm{P} / \mathrm{C}, a_{51}=\mathrm{N} / \mathrm{C}, a_{81}=-1$, and for $b_{m j}$ in Eq. (A2) to $b_{11}=1, b_{21}=\mathrm{N} / \mathrm{C}$, $b_{31}=\mathrm{P} / \mathrm{C}$.

- anaerobic degradation

- DNR (denitrification) $(j=2)$

$$
\begin{gathered}
R_{\mathrm{POC}}^{\mathrm{DNR}}=r_{2} \cdot T_{\mathrm{fac}}(T) \cdot\left(1-\frac{\left[\mathrm{O}_{2}\right]}{\left[\mathrm{O}_{2}{ }^{\text {half }}\right]+\left[\mathrm{O}_{2}\right]}\right) \\
\cdot \min \left(\frac{\frac{1}{2}\left[\mathrm{NO}_{3}^{-}\right]}{\text {nitdem }} ;[\mathrm{POC}]\right)
\end{gathered}
$$

With turnover rate $r_{2}$ (see Table 1), $a_{12}=$ $1, a_{22}=$ nitdem, $a_{32}=1, a_{42}=-1, a_{62}=1$, $b_{12}=1, b_{22}=\mathrm{N} / \mathrm{P}, b_{32}=\mathrm{P} / \mathrm{C}$.

- $\mathrm{SR}$ (sulfate reduction) $(j=3)$

$$
R_{\mathrm{POCs}}^{\mathrm{SR}}=r_{3} \cdot T_{\mathrm{fac}}(T) \cdot \min \left(\frac{[\mathrm{TA}]}{\mathrm{d}} ;[\mathrm{POC}]\right)
$$

With turnover rate $r_{3}$ (see Table 1), $a_{13}=1$, $a_{23}=\mathrm{N} / \mathrm{P}, \quad a_{33}=1, \quad a_{53}=1, \quad b_{13}=1$, $b_{23}=\mathrm{N} / \mathrm{C}, b_{33}=\mathrm{P} / \mathrm{C}$.

- $\mathrm{CaCO}_{3}$ dissolution $(j=4)$

$$
\begin{aligned}
& R_{\mathrm{CaCO}_{3}}=r_{4} \cdot T_{\mathrm{fac}}(T) \cdot\left[\mathrm{CaCO}_{3}\right] \\
& \quad \cdot\left(\max \left(\left[\mathrm{CO}_{3}^{2-}\right]^{\mathrm{sat}}-\left[\mathrm{CO}_{3}^{2-}\right] ; 0\right)\right)
\end{aligned}
$$

With turnover rate $r_{4}$ (see Table 1), $a_{14}=1, a_{24}=2$, $b_{44}=1$.

$\left[\mathrm{CO}_{3}^{2-}\right]^{\text {sat }}=\frac{\mathrm{ksp}}{[\mathrm{Ca}]}$

ksp: apparent pressure-corrected solubility product of calcite $[\mathrm{Ca}]=10.3 \mathrm{~mol} \mathrm{~m}^{-3}$ : calcium concentration.

- $\mathrm{SiO}_{2}$ (opal dissolution) $(j=5)$

$$
\begin{aligned}
& R_{\mathrm{SiO}_{2}}=\left[\mathrm{SiO}_{2}\right] \cdot r_{5} \cdot T_{\mathrm{fac}}(T) \\
& \cdot\left(\left[\mathrm{Si}(\mathrm{OH})_{4}\right]^{\mathrm{sat}}-\left[\mathrm{Si}(\mathrm{OH})_{4}\right]\right)
\end{aligned}
$$

With turnover rate $r_{5}$ (see Table 1), $a_{75}=1, b_{55}=1$.

$\left[\mathrm{Si}(\mathrm{OH})_{4}\right]^{\mathrm{sat}}=1 \mathrm{~mol} \mathrm{~m}^{-3}$

- $\mathrm{NH}_{4}$ (nitrification) $(j=6)$

$R_{\mathrm{NH}_{4}}^{\mathrm{NO}_{3}}=r_{6} \cdot T_{\mathrm{fac}}(T) \cdot\left[\mathrm{NH}_{4}\right]$

With turnover rate $r_{6}$ (see Table 1), $a_{26}=-2, a_{46}=1$, $a_{56}=-1$.

with $T_{\text {fac }}(T)=1.2^{\frac{T-T_{0}}{T_{0}}}$ with $T_{0}=10^{\circ} \mathrm{C}$.

\section{A3 Reaction equations and stoichiometry}

\section{A3.1 Incomplete aerobic remineralization (following Paulmier et al., 2009)}

$$
\begin{aligned}
& \mathrm{C}_{a} \mathrm{H}_{b} \mathrm{O}_{c} \mathrm{~N}_{d} P+\left(a+\frac{1}{4} b-\frac{1}{2} c-\frac{3}{4} d+\frac{5}{4}\right) \cdot \mathrm{O}_{2} \\
& \longrightarrow a \cdot \mathrm{CO}_{2}+d \cdot \mathrm{NH}_{3}+\mathrm{H}_{3} \mathrm{PO}_{4}+\left(\frac{1}{2} b-\frac{3}{2} d-\frac{3}{2}\right) \mathrm{H}_{2} \mathrm{O}, \\
& a=\mathrm{C} / P, b=\mathrm{H} / P, c=\mathrm{O} / P \text {, and } d=\mathrm{N} / P .
\end{aligned}
$$


J. Pätsch et al.: Interannual sedimentary effluxes of alkalinity in the southern North Sea

3307

A3.2 Complete denitrification (following Paulmier et al., 2009)

$$
\begin{aligned}
\mathrm{C}_{a} \mathrm{H}_{b} \mathrm{O}_{c} \mathrm{~N}_{d} P & +(\underbrace{\frac{4}{5} a+\frac{1}{5} b-\frac{2}{5} c+1}_{=\text {nitdem }}) \cdot \mathrm{HNO}_{3} \\
\longrightarrow & a \cdot \mathrm{CO}_{2}+\mathrm{H}_{3} \mathrm{PO}_{4}+\left(\frac{2}{5} a+\frac{3}{5} b-\frac{1}{5} c-1\right) \cdot \mathrm{H}_{2} \mathrm{O} \\
+ & \left(\frac{2}{5} a+\frac{1}{10} b-\frac{1}{5} c+\frac{1}{2} d+\frac{1}{2}\right) \cdot \mathrm{N}_{2}
\end{aligned}
$$

A3.3 Sulfate reduction

For $\left[\mathrm{O}_{2}\right]<1 \mu \mathrm{M}$ and $\left[\mathrm{NO}_{3}\right]<1 \mu \mathrm{M}$ :

$$
\begin{aligned}
\mathrm{C}_{a} \mathrm{H}_{b} \mathrm{O}_{c} \mathrm{~N}_{d} P+\left(\frac{1}{2} a+\frac{1}{8} b-\frac{1}{4} c-\frac{3}{8} d+\frac{5}{8}\right) \cdot \mathrm{H}_{2} \mathrm{SO}_{4} \\
\longrightarrow a \cdot \mathrm{CO}_{2}+d \cdot \mathrm{NH}_{3}+\mathrm{H}_{3} \mathrm{PO}_{4}+\left(\frac{1}{2} b-\frac{3}{2} d-\frac{3}{2}\right) \cdot \mathrm{H}_{2} \mathrm{O} \\
\quad+\left(\frac{1}{2} a+\frac{1}{8} b-\frac{1}{4} c-\frac{3}{8} d+\frac{5}{8}\right) \cdot \mathrm{H}_{2} \mathrm{~S} .
\end{aligned}
$$

A3.4 Nitrification of ammonia to nitrate

For $\left[\mathrm{O}_{2}\right]>1 \mu \mathrm{M}$ :

$$
\mathrm{NH}_{3}+2 \cdot \mathrm{O}_{2} \longrightarrow \mathrm{HNO}_{3}+\mathrm{H}_{2} \mathrm{O} \text {. }
$$

A4 Alkalinity generation

$$
R_{\mathrm{TA}}=\mathrm{d} \cdot R_{\mathrm{POC}}^{\mathrm{AD}}+\text { nitdem } \cdot R_{\mathrm{POC}}^{\mathrm{DNR}}+\mathrm{d} \cdot R_{\mathrm{POCs}}^{\mathrm{SR}}+2 \cdot\left(R_{\mathrm{CaCO}_{3}}-R_{\mathrm{NH}_{4}}^{\mathrm{NO}_{3}}\right)
$$

www.biogeosciences.net/15/3293/2018/

Biogeosciences, 15, 3293-3309, 2018 
Competing interests. The authors declare that they have no conflict of interest.

Special issue statement. This article is part of the special issue "Progress in quantifying ocean biogeochemistry - in honour of Ernst Maier-Reimer". It is not associated with a conference.

Acknowledgements. This work was supported by the Cluster of Excellence CliSAP (EXC177), University of Hamburg, funded by the German Science Foundation (DFG). We thank Ernst MaierReimer, who can be immediately identified as a coauthor of the model code, Helmuth Thomas, Hermann Lenhart, Alberto Borges, Markus Kreus, Fabian Schwichtenberg, Jana Friedrich, Andreas Neumann, and Fabian Große for valuable discussions. The model simulation was conducted on MISTRAL mainframe at the German Climate Computing Centre (DKRZ) in Hamburg.

Edited by: Joachim Segschneider

Reviewed by: Helmuth Thomas and one anonymous referee

\section{References}

Arakawa, A. and Lamb, V.: omputational design of the basic dynamical processes of the UCLA general circulation model, in: General Circulation Models of the Atmosphere, 17, Methods in Computational Physics: Advances in Research and Applications, London, Elsevier, edited by: Chang, J., 173-265, 1977.

Backhaus, J.: A three-dimensional model for the simulation of shelf sea dynamics, Ocean Dynam., 38, 165-187, https://doi.org/10.1007/BF02328975, 1985.

Bockelmann, F.-D., Puls, W., Kleeberg, U., Müller, D., and Emeis, K.-C.: Mapping mud content and median grain-size of North Sea sediments - A geostatistical approach, Mar. Geol., 397, 60-71, 2018.

Bozec, Y., Thomas, H., Schiettecatte, L.-S., Borges, A. V., De Elkalay, K., and Baar, H. J. W.: Assessment of processes controlling seasonal variations of dissolved inorganic carbon in the North Sea, Limnol. Oceanogr., 51, 2746-2762, 2006.

Brenner, H., Braeckman, U., Le Guitton, M., and Meysman, F. J. R.: The impact of sedimentary alkalinity release on the water column $\mathrm{CO}_{2}$ system in the North Sea, Biogeosciences, 13, 841863, https://doi.org/10.5194/bg-13-841-2016, 2016.

Burdige, D. J. and Komada, T.: Using ammonium pore water profiles to assess stoichiometry of deep remineralization processes in methanogenic continental margin sediments, Geochem. Geophy. Geosy., 14, 1626-1643, 2013.

Burt, W. J., Thomas, Pätsch, J., Omar, A. M., Schrum, C., Daewel, I., Brenner, H., and de Baar, H. J .W.: Radium isotopes as tracer of sediment-water column exchange in the North Sea, Global Biogeochem. Cy., 28, 786-804, 2014.

de Haas, H., van Weering, T. C. E., and de Stigter, H.: Organic carbon in shelf seas: sinks or sources, processes and products, Cont. Shelf Res., 22, 691-717, 2002.

Friedrich, J., van Beusekom, J., Neumann, A., and Naderipour, C.: Towards an integrated view of benthic and pelagic processes in the southern North Sea (German Bight), Geophys. Res. Abstracts, 17, EGU2015-9199, 2015.

Große, F., Greenwood, N., Kreus, M., Lenhart, H.-J., Machoczek, D., Pätsch, J., Salt, L., and Thomas, H.: Looking beyond stratification: a model-based analysis of the biological drivers of oxygen deficiency in the North Sea, Biogeosciences, 13, 2511-2535, https://doi.org/10.5194/bg-13-2511-2016, 2016.

Gypens, N., Lancelot, C., and Soetaert, K.: Simple parameterisations for describing $\mathrm{N}$ and $\mathrm{P}$ diagenetic processes: Application in the North Sea, Prog. Oceanogr., 76, 89-110, 2008.

Heinze, C., Maier-Reimer, E., Winguth, A. M. E., and Archer, D.: A global oceanic sediment model for long-term climate studies, Global Biogeochem. Cy., 13, 221-250, 1999.

Kalnay, E., Kanamitsu, M., Kistler, R., Collins, W., Deaven, D., Gandin, L., Iredell, M., Saha, S., White, G., and Woollen, J.: The ncep/ncar 40-year reanalysis project, B. Am. Meteorol. Soc., 77, 437-471, 1996.

Lorkowski, I., Pätsch, J., Moll, A., and Kühn, W.: Interannual variability of carbon fluxes in the North Sea from 1970 to 2006 - Competing effects of abiotic and biotic drivers on the gas exchange of $\mathrm{CO}_{2}$, Estuar. Coast. Shelf Sci., 100, 38-57, https://doi.org/10.1016/j.ecss.2011.11.037, 2012.

Luff, R. and Moll, A.: Seasonal dynamics of the North Sea sediment using a three-dimensional coupled sediment-water model system, Cont. Shelf Res., 24, 1099-1127, 2004.

Neubacher, E. C., Parker, R. E., and Trimmer, M.: Short-term hypoxia alters the balance of the nitrogen cycle in coastal sediments, Limnol. Oceanogr., 56, 651-665, 2011.

Neumann, A., van Beusekom, J. E. E., Holtappels, M., and Emeis, K. C.: Nitrate consumption in sediments of the German Bight (North Sea), J. Sea Res., 127, 26-35, https://doi.org/10.1016/j.seares.2017.06.012 2017.

Pätsch, J. and Kühn, W.: Nitrogen and carbon cycling in the North Sea and exchange with the North Atlantic - a model study, Part I. Nitrogen budget and fluxes, Cont. Shelf Res., 28, 767-787, 2008.

Pätsch, J., Lenhart, H.-J., and Schütt, M.: Daily Loads of Nutrients, Total Alkalinity, Dissolved Inorganic Carbon and Dissolved Organic Carbon of the European Continental Rivers for the Years 1977-2014, Tech. Rep., Institut für Meereskunde, Universität, Hamburg, 2016.

Pätsch, J., Burchard, H., Dieterich, C., Gräwe, U., Gröger, M., Mathis, M., Kapitza, H., Bersch, M., Moll, A., Pohlmann, T., Su, J., Ho-Hagemann, H. T. M., Schulz, A., Elizalde, A., and Eden, C.: An evaluation of the North Sea circulation in global and regional models relevant for ecosystem simulations, Ocean Modell., 116, 75-90, 2017.

Pätsch, J., Serna, A., Dähnke, K., Schlarbaum, T., Johannsen, A., and Emeis, K.: Nitrogen cycling in the German Bight (SE North Sea) - Clues from modelling stable nitrogen isotopes, Cont. Shelf Res., 30, 203-213, 2010.

Paulmier, A., Kriest, I., and Oschlies, A.: Stoichiometries of remineralisation and denitrification in global biogeochemical ocean models, Biogeosciences, 6, 923-935, https://doi.org/10.5194/bg6-923-2009, 2009.

Pohlmann, T.: Predicting the thermocline in a circulation model of the North Sea, 1. Model description, calibration and verification, Cont. Shelf Res., 16, 131-146, 1996.

Radach, G. and Pätsch, J.: Variability of Continental Riverine Freshwater and Nutrient Inputs into the North Sea for the Years 1977- 
2000 and Its Consequences for the Assessment of Eutrophication, Estuar. Coast, 30, 66-81, 2007.

Ridgwell, A., Zondervan, I., Hargreaves, J. C., Bijma, J., and Lenton, T. M.: Assessing the potential long-term increase of oceanic fossil fuel $\mathrm{CO}_{2}$ uptake due to $\mathrm{CO}_{2}$-calcification feedback, Biogeosciences, 4, 481-492, https://doi.org/10.5194/bg-4481-2007, 2007.

Schöpp, W., Posch, M., Mylona, S., and Johansson, M.: Long-term development of acid deposition (1880-2030) in sensitive freshwater regions in Europe, Hydrol. Earth Syst. Sci., 7, 436-446, https://doi.org/10.5194/hess-7-436-2003, 2003.

Seitzinger, S. and Giblin, A. E.: Estimating denitrification in North Atlantic continental shelf sediments, Biogeochemistry, 35, 235260, 1996.
Serna, A., Pätsch, J., Dähnke, K., Wiesner, M. G., Hass, H. C., Zeiler, M., Hebbeln, D., and Emeis, K.-C.: History of anthropogenic nitrogen input to the German Bight/SE North Sea as reflected by nitrogen isotopes in surface sediments, sediment cores and hindcast models, Cont. Shelf Res., 30, 1626-1638, 2010.

Schwichtenberg, F.: Drivers of the carbonate system variability in the southern North Sea: River input, anaerobic alkalinity generation in the Wadden Sea and internal processes, Doktorarbeit/PhS, Universität Hamburg, Hamburg, Germany, 161 pp., 2013.

Thomas, H., Schiettecatte, L.-S., Suykens, K., Koné, Y. J. M., Shadwick, E. H., Prowe, A. E. F., Bozec, Y., de Baar, H. J. W., and Borges, A. V.: Enhanced ocean carbon storage from anaerobic alkalinity generation in coastal sediments, Biogeosciences, 6, 267274, https://doi.org/10.5194/bg-6-267-2009, 2009. 